\title{
Test of a modified rainfall-runoff model in large-scale river basins
}

\author{
S. Giakoumakis*, D. Tigkas \\ School of Rural and Surveying Eng., National Technical University of Athens, Greece \\ *e-mail: sgiakou@central.ntua.gr
}

\begin{abstract}
In this work a modified version of the well-known Simple Water Balance (SWB) model, comprising here three parameters instead of one, was used. Although simple, the model was tested in large-scale river basins in east-central Greece, upstream two hydrometric stations. The available historic runoff records comprised 19 hydrologic years each, on a monthly basis. Thirteen among them were used for calibrating the model, whereas the six subsequent, for validating it. Two different efficiency criteria were used as a measure of performance of the modified model. Their values, calculated for both calibration and validation stages, were close and relatively high. Thus, keeping in mind both the size and complexity of the river basins studied, one can conclude that the modified model, despite its simplistic concept and lumped form, fits satisfactorily the historic runoff series.
\end{abstract}

Key words: Rainfall-runoff model; large-scale river basins; calibration; validation

\section{INTRODUCTION}

Model in general is a simplified representation of a real-world system. Mulligan (2004), defined model as an abstraction of reality in the simplest way that is adequate for the purpose of the modelling. The best model, according to him, is always that which achieves the greatest realism with the least number of parameters and model complexity.

As rainfall-runoff model is defined a set of mathematical relationships that correlate rainfall with runoff (Nalbantis 2007). Depending upon the kind of equations used, rainfall-runoff models are divided into three general categories: 1 . black box, 2. conceptual and 3. physically-based.

Among them, conceptual rainfall-runoff models are a common tool for the assessment of runoff in river basins. Nevertheless, most of them include many parameters, which have to be estimated (Phanartzis 1972, Viessman et al. 1989, Crooks et al. 2014, Fowler et al. 2016, Sitterson et al. 2017). In order to overcome this disadvantage, in the present study the well known monoparametric Simple Water Balance (SWB) model (Diskin et al. 1973) was selected. More specifically, an improved version of this model has been used in such a way that it can also take into account both deep percolation losses and groundwater storage. Only two additional parameters were inserted.

The modified model was tested in Pinios river basin in east-central Greece, upstream Ali Efendi and Larissa hydrometric stations.

Our purpose was to show that, despite its minimalistic concept and lumped form, the modified SWB model performs satisfactorily, even in hydrologically complex river systems, such as these of the river basins chosen for this study.

\section{THEORY}

The SWB model is based on the assumption that the water storage in the river basin takes place in the upper soil zone (i.e. root zone) (Giakoumakis et al. 1991). In this work, a modified threeparametric version of this model has been used. A schematic representation of the modified model is given in Fig. 1. According to this figure, $S_{i}(\mathrm{~mm})$ represents the available water for any month $i$ (soil moisture) and $S_{\max }$ is a parameter representing the total soil storage capacity. The monthly soil 
$\underline{2}$

moisture deficit is then represented by the difference $S_{\max }-S_{i}$, averaged over the river basin. The water depth $S_{i}$ in the soil increases by the monthly precipitation $P_{i}$ and is depleted by both the monthly potential evapotranspiration $E_{i}$ and the deep percolation losses $D_{i}$.

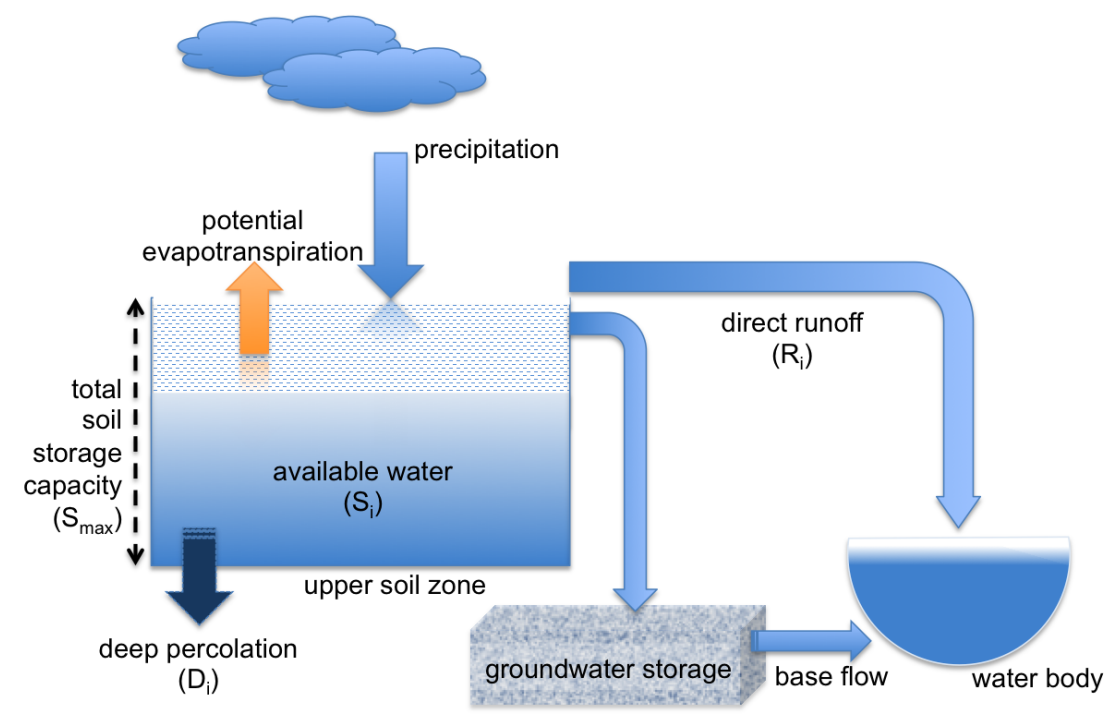

Figure 1. Schematic representation of the modified SWB model.

As a first step, a trial depth of the soil moisture $S_{i}{ }^{\prime}$ is computed by:

$$
S_{i}{ }^{\prime}=S_{i-1}+P_{i}-E_{i}(\mathrm{~mm})
$$

where:

$S_{i-1}:$ soil moisture for the month i-1 (mm)

$P_{i}$ : precipitation for the month i $(\mathrm{mm})$

$E_{i}:$ potential evapotranspiration for the month i (mm)

Monthly direct runoff $R_{i}$ (excess water) depends on the value of $S_{i}^{\prime}$ (Eq.1). Thus:

If $\mathrm{Si}^{\prime}>S_{\max }$

$$
\begin{aligned}
& R_{i}=\left(S_{i}{ }^{\prime}-S_{\text {max }}\right) \cdot K^{\prime} \\
& D_{i}=\left(S_{i}{ }^{\prime}-S_{\text {max }}\right) \cdot K \\
& S_{i}=S_{\text {max }}
\end{aligned}
$$

where:

$K^{\prime}=1-K$

$D_{i}$ : deep percolation losses for the month i (mm)

$K$ : deep percolation losses coefficient $(0 \leq K \leq 1$-C, where $\mathrm{C}$ runoff coefficient $)$

If $0 \leq S_{i}{ }^{\prime} \leq S_{\max }$

$$
R_{i}=0
$$

$S_{i}=S_{i}^{\prime}$

$D_{i}=0$ 


$$
\begin{aligned}
& \text { If } S_{i}{ }^{\prime}<0 \\
& R_{i}=0 \\
& S_{i}=0 \\
& D_{i}=0
\end{aligned}
$$

Runoff calculated from the above described model is mainly concentrated in the winter months, because the model does not take into account the groundwater storage. In order to overcome this disadvantage, the following equation is proposed:

$$
Q_{i}=a \cdot R_{i}+(1-a) \cdot Q_{i-1}
$$

where $Q_{i}$ is a second, more accurate, approximation of the runoff $R_{i}$ and 'a' is the lag parameter of the modified model $(0<a \leq 1)$. This parameter expresses the delay of rainfall's conversion to runoff. Values close to 0 correspond to a long delay and as a result, runoff is transposed to spring and summer months, whereas values close to 1 , correspond to an instant response of the river basin and thus, instant runoff formation.

The efficiency of each simulation performed, was checked by the well-known NSE coefficient, given from the following equation (Nash and Sutcliffe 1970):

$$
N S E=\left\{\sum\left(y_{o i}-\tilde{y}_{o}\right)^{2}-\sum\left(y_{o i}-y_{c i}\right)^{2}\right\} / \sum\left(y_{o i}-\tilde{y}_{o}\right)^{2}
$$

where:

$y_{o i}$ : observed monthly runoff for the month i $(\mathrm{mm})$

$\tilde{y}_{o}$ : mean value of observed monthly runoff $(\mathrm{mm})$

$y_{c i}$ : computed monthly runoff for the month $\mathrm{i}(\mathrm{mm})$

As an additional criterion for model performance was used the ratio of the sum of the computed monthly runoff over the sum of the observed monthly runoff (Mimikou et al. 1991):

$$
r=\sum y_{c i} / \sum y_{o i}
$$

The nearer to unity the values of NSE and $r$ calculated from Eq. (12) and Eq. (13) respectively are, the better the suitability of the model for describing the rainfall-runoff process.

\section{RESULTS AND DISCUSSION}

The modified model was implemented in Pinios river basin in Thessalia (east-central Greece) upstream two different hydrometric stations, i.e. Ali Efendi of an upstream basin area of $2714.4 \mathrm{~km}^{2}$ and Larissa, of an upstream area of $6529.7 \mathrm{~km}^{2}$ (Fig. 2). Pinios river basin is a huge flat plain surrounded by high mountains. The mean annual areal precipitation upstream Larissa hydrometric station is equal to $871.2 \mathrm{~mm}$ (Xanthopoulou et al. 1997). Geology of the Pinios river basin is mostly composed by flysch, limestone and alluvial deposits in lower altitude areas (Nalbantis and Koutsoyiannis 1997). 
4

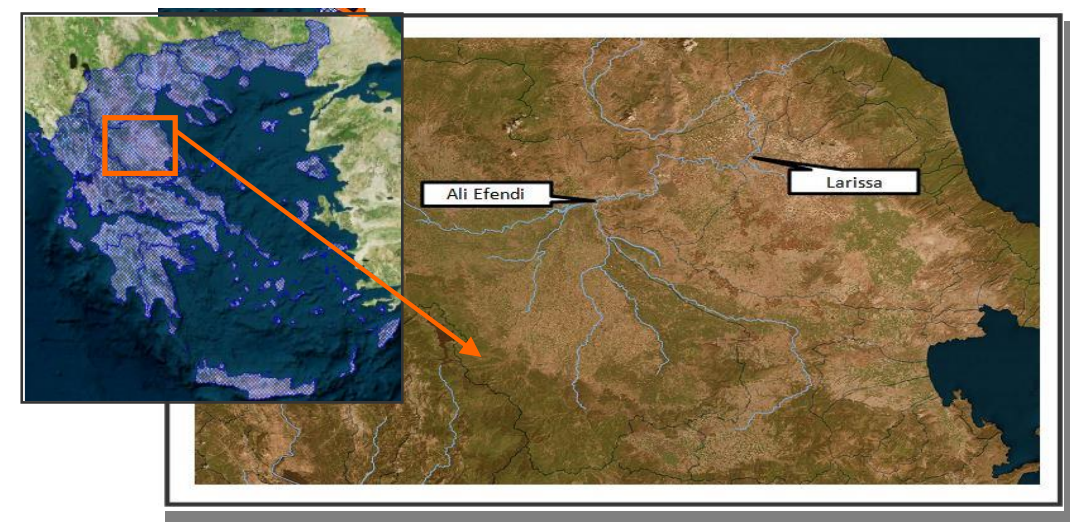

Figure 2. Studyarea: Pinios river basin (upstream Ali Efendi and Larissa hydrometric stations).

In Table 1 the main characteristics of each river basin at the sites of interest are presented (Xanthopoulou et al. 1997).

Table 1. Main characteristics of the river basins studied.

\begin{tabular}{lcc}
\hline $\begin{array}{l}\text { River basins' } \\
\text { characteristics }\end{array}$ & Ali Efendi & Larissa \\
\hline Area $\left(\mathrm{km}^{2}\right)$ & 2714.4 & 6529.7 \\
Mean elevation $(\mathrm{m})$ & 539.7 & 414.9 \\
\hline
\end{tabular}

Input data (monthly areal precipitation and potential evapotranspiration values) for feeding the model, concern a period of 19 hydrologic years for which, measured monthly runoff data were also available for each case considered (Nalbantis and Koutsoyiannis 1997). For the calibration of the model, data of the first 13 hydrologic years were used, whereas for the validation, data of the subsequent 6 hydrologic years of the 19 total available were taken. Calibration procedure was carried out by applying a trial and error technique (Tigkas and Tsakiris 2004, Tigkas et al. 2012). In Table 2 are presented the basic statistics on annual basis of the two historic runoff time series for Ali Efendi and Larissa hydrometric stations, respectively.

Table 2. Basic statistics of the historic runoff time series on annual basis.

\begin{tabular}{lcc}
\hline & Ali Efendi & Larissa \\
\hline M.A.R. $(\mathrm{mm})$ & 355.9 & 420.9 \\
STD $(\mathrm{mm})$ & 162.2 & 195.7 \\
\hline
\end{tabular}

In Table 3 the optimum set of values of the parameters of the model, determined during calibration, is presented for each case considered.

Table 3. Optimum set of values of model's parameters.

\begin{tabular}{ccc}
\hline Parameter & Ali Efendi & Larissa \\
\hline $\mathrm{S}_{\max }(\mathrm{mm})$ & 130.0 & 152.0 \\
$\mathrm{~K}$ & 0.05 & 0.12 \\
$\mathrm{a}$ & 0.45 & 0.48 \\
\hline
\end{tabular}

Both NSE and r values, for both calibration and validation periods, for the two cases considered, are summarized in Table 4. 
Table 4. Values of NSE and rfor calibration and validation periods.

\begin{tabular}{lcccc}
\hline \multirow{2}{*}{ River basin } & \multicolumn{2}{c}{ Calibration } & \multicolumn{2}{c}{ Validation } \\
& NSE & r & NSE & r \\
\hline Pinios (Ali Efendi) & 0.81 & 1.0 & 0.68 & 0.94 \\
Pinios (Larissa) & & & $0.65^{*}$ & $0.89^{*}$ \\
& 0.83 & 1.0 & 0.53 & 0.99 \\
\hline
\end{tabular}

$\left(^{*}\right)$ without considering the extreme runoff value of March 1987 (Fig. 3b)

In Fig. 3 results are presented on a monthly basis for: (a) Ali Efendi and (b) Larissa. It can be observed that simulated runoff follows the variations of the measured one for both calibration and validation periods, at the two sites considered, with the exception of the extremely high runoff value for March of the hydrologic year 1986-87 (last validation year/case of Larissa).
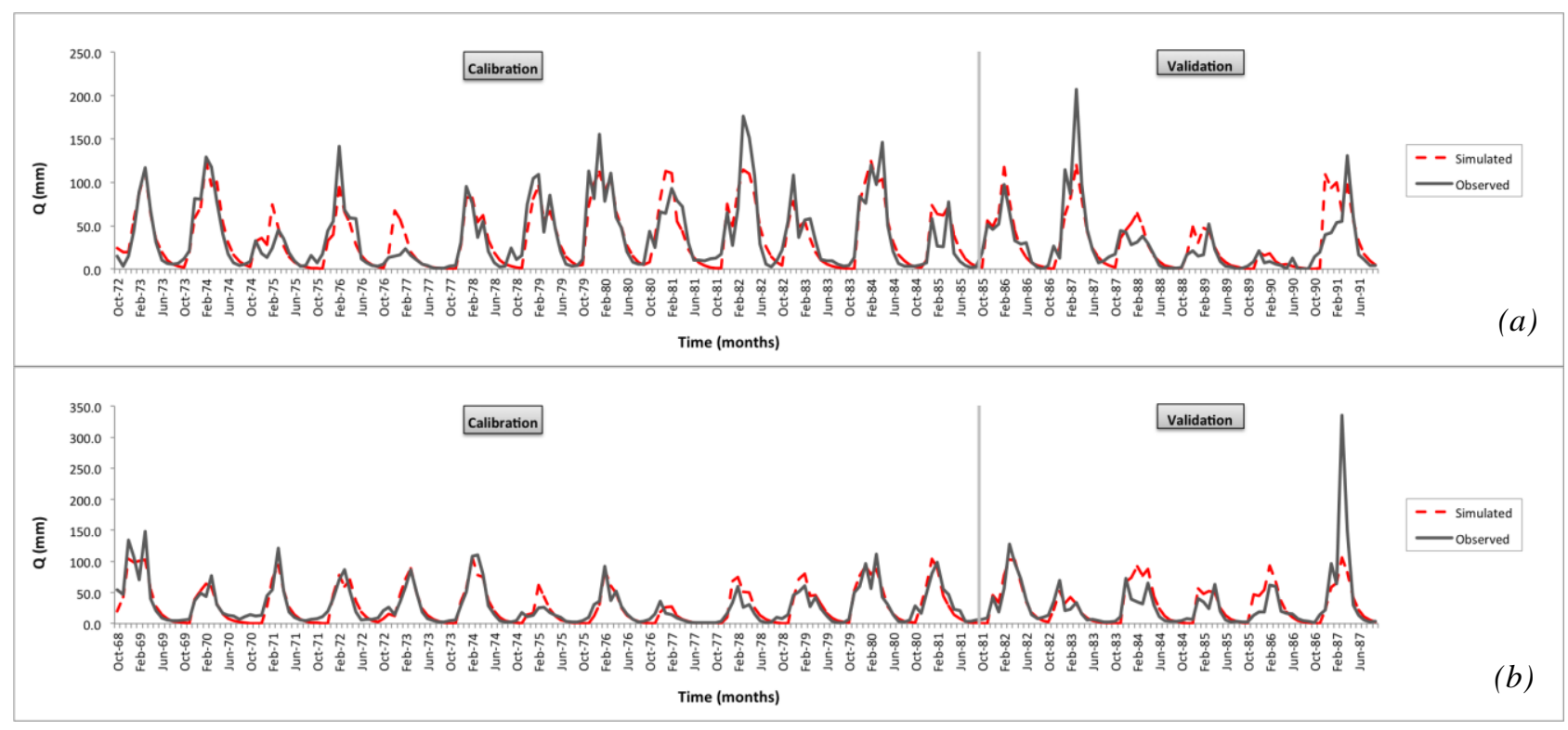

Figure 3. Monthly runoff variation for model's calibration and validation periods at: (a) Ali Efendi and (b) Larissa.

\section{CONCLUDING REMARKS}

A modified version of the well-known SWB model was used for estimating the rainfall-runoff relationship in large-scale river basins in east-central Greece.

Model calibration was performed using a 13-year runoff record on a monthly basis from Ali Efendi and Larissa hydrometric stations of the Pinios river basin. The suitability of the model was checked by the efficiency criteria NSE (Eq. 12) and r (Eq. 13). Model validation was carried out using monthly runoff data of the subsequent 6 hydrologic years of the available corresponding runoff series. It was shown that both NSE and $r$ values remained close to those of calibration and relatively high.

Satisfactory model's performance proved that the modified SWB, thanks to its simplicity, can be seen as a useful tool for no time consuming hydrologic simulation, even in complex and large-scale river basins.

\section{REFERENCES}

Crooks S.M., Kay A.L., Davies H.N. and Bell V.A., 2014. From Catchment to National Scale Rainfall-Runoff Modelling: Demonstration of a Hydrological Modelling Frameowrk. Hydrology 1(1), pp. 63-68.

Diskin M.H., Buras N., Zamir S., 1973. Application of a Simple Hydrologic Model for Rainfall-Runoff relations of the Dalton watershed. Water Resources Research, 9(4): 927-936. 
Fowler K.J.A., Peel M.C., Western A.W., Lu Zhang L., and Peterson T.J., 2016. Simulating runoff under changing climatic conditions: Revisiting an apparent deficiency of conceptual rainfall-runoff models, Water Resources Research Vol. 52(3): 18201846.

Giakoumakis S., Tsakiris G. and Efremides D., 1991. On the rainfall-runoff modelling in a Mediterranean island environment. Advances in Water Resources Technology, G. Tsakiris (ed.), Balkema, Rotterdam, pp. 137-148.

Mimikou M., Kouvopoulos Y., Cavadias G. and Vayianos N., 1991. Regional Hydrological Effects of Climate Change, Journal of Hydrology, 123:119-146.

Mulligan M., 2004. Modelling catchment hydrology. In Mulligan, M., Wainwright, J., (eds.), Environmental Modelling. London: Wiley, pp. 432.

Nalbantis I., 2007. Protection and Water Resources Management, NTUA, pp. 180.

Nalbantis I., Koutsoyiannis D., 1997. Research Project: Upgrading and Updating of Hydrological Information of Thessalia - Final Report, Vol. 4, National Technical University of Athens, Athens, Greece, pp. 78 (in Greek), Scientific Director: D. Koutsoyiannis, Principal Investigator: I. Nalbantis.

Nash, J. E. and Sutcliffe, J. V. 1970. River flow forecasting through conceptual models, Part I - A discussion of principles, Journal of Hydrology, 10(3): 282-290.

Phanartzis C. A., 1972. "Morphou - Tylliria Feasibility Studies". Simulation of watershed runoff in Morphou - Tylliria area. AGL:SF/CYP.513, Technical Report.

Sitterson J., Knightes C., Parmar R., Wolfe K., Muche M., Avant B., 2017. An Overview of Rainfall-Runoff Model Types, EPA/600/R-14/152.

Tigkas D., Tsakiris G., 2004. Medbasin: A Mediterranean rainfall - runoff software package, European Water, 5/6: 3-11.

Tigkas D., Vangelis H., Tsakiris G., 2012. Drought and climatic change impact on streamflow in small watersheds. Science of the Total Environment, 440: 33-41.

Viessman W., Lewis G.L., Knapp J.W., 1989. Introduction to Hydrology, third edition, Harper \& Row, Publishers, New York.

Xanthopoulou E. Mamassis N., Anastasopoulou P., Alexopoulou K., 1997. Research Project:Upgrading and Updating of Hydrological Information of Thessalia - Updating of hydrometeorological data, Vol. 1, National Technical University of Athen s, Athens, Greece, pp. 240 (in Greek), Scientific Director: D. Koutsoyiannis, Principal Investigator: I. Nalbantis. 